\title{
High incidence of primary pulmonary hypertension associated with appetite suppressants in Belgium
}

\author{
M. Delcroix*, X. Kurz+, D. Walckiers', M. Demedts*, R. Naeije**
}

High incidence of primary pulmonary hypertension associated with appetite suppressants in Belgium. M. Delcroix, X. Kurz, D. Walckiers, M. Demedts, R. Naeije. (CERS Journals Ltd 1998.

ABSTRACT: Primary pulmonary hypertension is a rare, progressive and incurable disease, which has been associated with the intake of appetite suppressant drugs. The importance of this association was evaluated in Belgium while this country still had no restriction on the prescription of appetite suppressants.

Thirty-five patients with primary pulmonary hypertension and 85 matched controls were recruited over 32 months (1992-1994) in Belgium. Exposure to appetite-suppressants was assessed on the basis of hospital records and standardized interview.

Twenty-three of the patients had previously taken appetite suppressants, mainly fenfluramines, as compared with only 5 of the controls $(66$ versus $6 \%, p<0.0001)$. Five patients died before the interview, all of them had taken appetite suppressants. In 8 patients the diagnosis of primary pulmonary hypertension was uncertain, 5 of them had taken appetite suppressants. The patients who had been exposed to appetite suppressants tended to be on average more severely ill, and to have a shorter median delay between onset of symptoms and diagnosis.

A policy of unrestricted prescription of appetite suppressants may lead to a high incidence of associated primary pulmonary hypertension. Intake of appetite suppressants may accelerate the progression of the disease.

Eur Respir J 1998; 12: 271-276.
*Dept of Pneumology, Gasthuisberg University Hospital, Leuven. **Dept of Intensive Care, Erasme University Hospital, Brussels. +Dept of Epidemio-Toxicology, Institute of Hygiene and Epidemiology, Brussels.

Correspondence: M. Delcroix, Dept of Pneumology, Gasthuisberg University Hospital, Herestraat, 49, 3000 Leuven, Belgium Fax: 3216346803

Keywords: Appetite suppressants fenfluramines

primary pulmonary hypertension

Received: October 291997

Accepted after revision April 301998

This study was supported by grant \#9404UO 27203-UI-A from the Industry Program of the Medical Research Council of Canada, by the Institut de Recherches Internationales Servier, and by the Ministry of Public Health and Environment of Belgium.
Primary pulmonary hypertension is a rare, progressive and incurable disease [1]. Its aetiology is still unknown, although portal hypertension, human immunodeficiency virus infection, intake of toxins, and appetite-suppressants have been implicated in some patients [1]. At the end of the 1960s, an epidemic of pulmonary hypertension occurred in Germany, Switzerland and Austria after the introduction of the appetite-suppressant aminorex [2]. In the early 1990s, French investigators reported a cluster of cases associated with the intake of fenfluramine or its Disomer dexfenfluramine [3]. The suspicion that fenfluramines also carry an increased risk of pulmonary hypertension pro-mpted an international case-control study, the International Primary Pulmonary Hypertension Study (IPPHS). Based on the analysis of 95 cases and 355 controls re-cruited in France, Belgium, the UK, and the Netherlands, the IPPHS reported an odds ratio of 23 for cases of prim-ary pulmonary hypertension exposed to appetite suppressants (mainly fenfluramines) for $>3$ months [4]. However, surprisingly, these results did not prevent the approval of dexfenfluramine for the treatment of obesity in the USA by the Food and Drug Administration [5, 6].

The Belgian contribution to the IPPHS was characterized by the highest level of intake of appetite suppressants and by the highest number of included patients per population. However, because of the stringent inclusion criteria of the IPPHS, only a minority of these patients could be reported. We therefore thought it of interest to describe the Belgium experience in detail, as an illustration of the dire consequences of a policy of unrestricted prescription of appetite suppressant drugs.

\section{Patients and methods}

\section{Patients}

The study included Belgian residents of both sexes, aged 18-70 yrs, with primary pulmonary hypertension diagnosed between January 1992 and September 1994. The diagnosis required both the documentation of pulmonary hypertension, with a mean pulmonary arterial pressure $(P$ pa $)>25 \mathrm{mmHg}$, and the absence of the following secondary causes: congenital abnormalities of lungs, thorax or diaphragm; congenital or acquired valvular or myocardial disease; pulmonary thromboembolism; obstructive lung disease; interstitial lung disease; pulmonary artery or pulmonary valve stenosis; pulmonary venous hypertension; central hypoventilation with hypoxaemia and hypercapnia; parasitic disease affecting the lungs; sickle cell anaemia; acquired immunodeficiency syndrome; collagen vascular diseases; and active liver disease or portal hypertension. To exclude secondary pulmonary hypertension, an algorithm 
was used based on a mandatory chest radiograph, respiratory function, perfusion lung scan, echocardiogram, right heart catheterization, and arterial blood gases [7].

Sixty-four cardiology and pneumology centres at large or university-based hospitals were contacted and agreed to participate in the study. The reported cases were screened for inclusion criteria on site by a trained pneumologist, and medical data were extracted from the hospital records. Thereafter, the cases were reviewed by an international panel of experts. The panel classified the cases into three groups with respect to the diagnosis of primary pulmonary hypertension as appropriate, possibly appropriate, and inappropriate. Only the first two categories were included in the IPPHS. The last category included patients in whom the primary nature of the pulmonary hypertension was in some way questionable. Because of the prospective recruitment required for the IPPHS, the cases were divided into "prevalent" cases (diagnosed before September 1992) and "incident" cases (diagnosed after the launching of the study in September 1992). The prevalent cases were also excluded from the IPPHS.

\section{Controls}

Controls were randomly selected from lists of consecutive patients seen by the same general practitioner, or, if this physician was unavailable, by other general practitioners in the same geographical area. The controls were individually matched to the patients with respect to age, sex, and the number of visits to the physician per year before the diagnosis of primary pulmonary hypertension. There were controls only for the patients who could be interviewed, which explains why the initial aim of 4 controls per case as in the IPPHS [4] could not be attained for the 35 patients included in the present study.

\section{Exposure to appetite-suppressants}

The exposure to appetite suppressants was evaluated firstly through data extracted from the patients' hospital records, secondly through a thorough face-to-face interview with the patients and with their matched controls by specially trained interviewers without any medical background. The subjects were asked about their medical history, and exposure to drugs. Drug use was established firstly by spontaneous reporting by the patient, secondly by presenting the patient lists of $\sim 80$ trade names chosen from the most commonly prescribed drugs in 17 therapeutic classes, and thirdly by presenting the patient a visual display showing 35 selected packages, tablets, or both. Only exposure to anorectic agents was analysed. The following appetite suppressants were considered: 1) fenfluramines (fenfluramine racemate and dexfenfluramine); 2) other amphetamine-like agents (diethylpropion also called amfepramone, phentermine, etc.); and 3) compound preparations of appetite suppressants, further called "magistral preparations". For each patient and their matched controls, the index date used to assess exposure corresponded to the date of the onset of symptoms (usually dyspnoea) taken from the hospital record.

The patients were classified as having been exposed to a given risk factor if the exposure occurred before the index date ("definite" exposure). A "possible" exposure was also retained when it occurred at an indeterminate time, or when exposure was reported in the hospital chart but not confirmed by the interview. Patients in whom the exposure began after the index date were considered as unexposed. Exposed cases as well as controls were further divided into "recent users", if the exposure occurred in the 12 months preceding the index date, and "past users", if the exposure had ended more than 12 months earlier.

\section{Statistical analysis}

A bilateral Student's t-test, for equal or unequal variances as needed [8], was used to compare the exposure in cases and controls, and the clinical data (presented as mean \pm sD) in exposed and nonexposed cases. Survival from diagnostic catheterization until the end of the follow-up period (date of most recent information on the patient ending in March 1996, or transplantation, or death) were estimated by the Kaplan-Meier method survival curve. Differences in mean survival time were tested with the logrank test (SPSS statistical package for Windows, version 6; SPSS Inc, Chicago, IL, USA). A p-value $<0.05$ was considered to indicate statistical significance.

\section{Results}

\section{Case recruitment}

Thirty-five patients were reported as meeting the inclusion criteria of the IPPHS between January 1992 and September 1994 in Belgium. Five patients died before the interview. Eleven patients were excluded from the IPPHS as "prevalent" cases. In 8 patients (including 2 of the patients who died before the interview), the diagnosis of primary pulmonary hypertension was considered questionable by the expert IPPHS panel. Accordingly, 13 of the 35 patients reported here were included in the IPPHS.

The 8 cases considered inappropriate by the expert panel of the IPPHS presented respectively as follows: 1) had a history of rheumatoid arthritis, bi-apical ground glass appearance on high-resolution computed tomography (CT)-scan, but normal lung volumes and typical lesions of primary pulmonary hypertension at post mortem histopathological examination; 2) had a diffusing capacity for carbon monoxide of $33 \%$ of the predicted value, micronodules at high-resolution CT-scan, but a microscopic aspect suggestive of pulmonary veno-occlusive disease at open lung biopsy; 3) had a possible atrial septal defect at echocardiographic examination, but no left-to-right shunt through Doppler examination, left heart ventriculography, and staged oximetry; 4) had a probable mixed connective tissue disease, with speckled anti-nuclear antibodies (1: 320), a positive extractable nuclear antigen (ENA) titre for anti-ribonucleoprotein, and previous pleural effusion and an alveolar bleeding; 5) had an isolated 50\% decrease in forced vital capacity (FVC); 6) had a 50\% decrease in FVC and a ground glass aspect on high-resolution CT-scan, but a normal chest radiograph; 7) had a low probability ventilation/perfusion lung scan for pulmonary embolism; and 8) had a transiently high pulmonary artery wedge pressure of $31 \mathrm{mmHg}$, but no altered left ventricular systolic 
function or mitral valve disease at echocardiography, and attributed to altered left ventricular diastolic compliance due to extreme right ventricular dilatation after reversal by fluid restriction and an infusion of dobutamine. It is to be noted that in the American National Institute of Health (NIH) Registry of Primary Pulmonary Hypertension, a high-resolution CT-scan was not required, and an isolated decrease in FVC, a positive result of anti-nuclear antibody test or a low probability ventilation/perfusion lung scan were not considered as exclusion criteria [7]. In fact, all the 8 cases rejected by the very stringent criteria of the IPPHS expert panel had a reasonably well established diagnosis of primary pulmonary hypertension based on exclusion of all possible secondary causes, clinical evaluation and haemodynamic assessment, and were therefore included in the present study.

\section{Incidence}

The 64 participating centres were repeatedly contacted to obtain an exhaustive recruitment of the cases in Belgium. This allowed us to calculate an annual incidence of 1.9 cases per million persons $(95 \%$ confidence interval: 0-8.0): 35 cases were reported over 32 months (from January 1992 to September 1994) for a population of 6.9 million persons aged $18-70$ yrs.

\section{Exposure to appetite suppressants}

Details on exposure to appetite suppressants in patients and in controls are shown in table 1. According to the hospital charts, 21 of the 35 patients had previously taken appetite suppressants. The interviews (unavailable for the 5 patients who died before the interview and for the latest included patient) gave a positive exposure to appetite suppressants in 14 patients. The information found in the

Table 1. - Frequency of appetite suppressants exposure in the patients $(n=35)$ and controls $(n=85)$

\begin{tabular}{lcc}
\hline & Cases & Controls \\
\hline All exposure & $23(65.7)$ & $5(5.9)$ \\
Definite exposure & $17(48.6)$ & $5(5.9)$ \\
Delay between exposure and & symptoms & \\
ð1 yr & $11(31.4)$ & $1(1.2)$ \\
$>1$ yr & $7(20.0)$ & $4(4.7)$ \\
Unknown & $5(14.3)$ & 0 \\
Cumulated duration of use & $3(8.6)$ & $2(2.4)$ \\
ð3 months & $12(34.3)$ & $1(1.2)$ \\
$>3$ months & $8(22.9)$ & $2(2.4)$ \\
Unknown & $6(17.1)$ & $2(2.4)$ \\
Reported compounds (numbers are not mutually exclusive) \\
Dexfenfluramine & $12(34.3)$ & $2(2.4)$ \\
Fenfluramine & $8(22.9)$ & $1(1.2)$ \\
Diethylpropion & $2(5.7)$ & 0 \\
Phentermine & $13(37.0)$ & 0 \\
Magistral & & \\
Pure agents & $3(8.6)$ & $2(2.4)$ \\
Dexfenfluramine only & $1(2.9)$ & $2(2.4)$ \\
Fenfluramine only & $3(8.6)$ & $5(5.9)$ \\
Exposure after index date &
\end{tabular}

Data are presented as number of subjects with percentages in parentheses. hospital records and the information assessed from the interview were discrepant in 5 patients. Two patients had a positive interview and a negative hospital chart. Thus, 23 of the 35 patients had a history of previous intake of appetite suppressants. A total of 85 controls were available for $79 \%$ of the interviewed cases. Five of these controls had a history of previous appetite suppressant intake.

As shown in table 1, most patients were recent users (in the year before the index date), and had taken appetite suppressants for $>3$ months. Appetite suppressants were most often taken as magistral preparations (which usually contained fenfluramine, at a dose of $12-80 \mathrm{mg} \cdot \mathrm{day}^{-1}$, and diethylpropion, at a dose of $20-150 \mathrm{mg}^{-} \mathrm{day}^{-1}$ ). At least 7 patients had taken a combination of fenfluramine and diethylpropion, and 2 patients a combination of fenfluramine and phentermine.

There was a history of previous intake of appetite suppressants in the 5 patients who died before the interview, and in 5 of the 8 patients considered inappropriate by the panel of experts of the IPPHS.

\section{Clinical data}

The clinical characteristics of the present patients with primary pulmonary hypertension as compared to those of the global IPPHS [4] and the NIH Registry [7] are shown in table 2. In the Belgian patients, mean age and haemodynamic data were similar, the female to male ratio was higher, dyspnoea at diagnosis was on average somewhat milder, and the delay between symptoms and catheterization tended to be shorter. The median delay between onset of symptoms and diagnosis was 7 months for the Belgian patients whereas it was 16 months and 15 months for the global IPPHS and for the NIH Registry patients, respectively.

A comparison between Belgian patients with or without previous intake of appetite suppressants is presented in table 3. The patients with previous intake of appetite suppressants had a significantly higher body mass index (BMI). They also tended to have a clinically relevant (but not statistically significant) more severe form of the disease as assessed by more patients in the New York Heart Association (NYHA) classification of dyspnoea class III and IV at time of the diagnosis, a shorter median delay between the onset of symptoms and the diagnosis, slightly lower cardiac output and mixed venous oxygenation, and higher total pulmonary vascular resistance. No correlation was found, however, between the duration of the exposure and the severity of pulmonary hypertension as assessed by pulmonary artery pressures or total pulmonary vascular resistance.

\section{Survival}

The probability of survival tended to be lower for the patients with previous intake of appetite suppressants, but not significantly so. Estimated percentages of patients surviving at 1 and 3 yrs respectively were $72 \%$ and $54 \%$ for the exposed cases, and $100 \%$ and $78 \%$ for the nonexposed cases.

Twelve of the 35 patients underwent lung transplantation during the observation period which ended in March 
Table 2. - Clinical data of 35 patients compared with those of the International Primary Pulmonary Hypertension Study (IPPHS) ( $n=95)$ and the American National Institute of Health (NIH) Registry $(n=187)$

\begin{tabular}{|c|c|c|c|}
\hline & Belgium & IPPHS & $\mathrm{NIH}$ \\
\hline Age yrs & $44 \pm 13$ & $45 \pm 12$ & $36 \pm 15$ \\
\hline Female to male ratio & $3.4: 1$ & $2.3: 1$ & $1.7: 1$ \\
\hline \multicolumn{4}{|l|}{ Initial symptoms $\%$} \\
\hline Dyspnoea & 89 & 91 & 60 \\
\hline Angina pectoris & 23 & 16 & 7 \\
\hline Syncope & 14 & 14 & 13 \\
\hline Oedema & 12 & 9 & 3 \\
\hline \multicolumn{4}{|l|}{ Severity of dyspnoea at diagnosis $\%$} \\
\hline NYHA class I and II & 54 & 34 & 29 \\
\hline NYHA class III and IV & 46 & 66 & 71 \\
\hline \multicolumn{4}{|l|}{ Delay between catheterization and symptoms $\%$} \\
\hline ð12 months & 66 & 37 & - \\
\hline $13-35$ months & 31 & 39 & - \\
\hline Š36 months & 3 & 20 & - \\
\hline Mean pulmonary arterial pressure $\mathrm{mmHg}$ & $53 \pm 13$ & $57 \pm 13$ & $60 \pm 18$ \\
\hline Cardiac output $\mathrm{L} \cdot \mathrm{min}^{-1} \cdot \mathrm{m}^{-2}$ & $2.2 \pm 0.7$ & 2.3 & $2.3 \pm 0.9$ \\
\hline Pulmonary artery wedge pressure $\mathrm{mmHg}$ & $10 \pm 7$ & $9 \pm 3$ & $8 \pm 4$ \\
\hline Right atrial pressure $\mathrm{mmHg}$ & $10 \pm 8$ & $11 \pm 6$ & $10 \pm 6$ \\
\hline
\end{tabular}

NYHA: New York Heart Association classification of dyspnoea.

Table 3. - Comparison of clinical and haemodynamic data of 35 patients with primary pulmonary hypertension, exposed $(n=23)$ versus nonexposed $(n=12)$ to appetite suppressants

\begin{tabular}{|c|c|c|c|}
\hline & Exposed & Nonexposed & $\mathrm{p}$ \\
\hline Age yrs & $44 \pm 13$ & $42 \pm 13$ & NS \\
\hline BMI & $31 \pm 6$ & $25 \pm 5$ & 0.01 \\
\hline NYHA class III and IV \% & 61 & 17 & 0.01 \\
\hline Median delay from onset of symptoms to diagnosis months & 7 & 10 & NS \\
\hline Mean pulmonary arterial pressure $\mathrm{mmHg}$ & $54 \pm 15$ & $52 \pm 9$ & NS \\
\hline Cardiac output $\mathrm{L} \cdot \mathrm{min}^{-1} \cdot \mathrm{m}^{-2}$ & $2.0 \pm 0.7$ & $2.4 \pm 0.7$ & NS $(p=0.2)$ \\
\hline Total pulmonary vascular resistance $\mathrm{dyne} \cdot \mathrm{s} \cdot \mathrm{cm}^{-5} \cdot \mathrm{m}^{2}$ & $2457 \pm 1451$ & $1885 \pm 616$ & NS $(\mathrm{p}=0.2)$ \\
\hline Pulmonary artery wedge pressure $\mathrm{mmHg}$ & $12 \pm 8$ & $7 \pm 4$ & NS $(p=0.06)$ \\
\hline Right atrial pressure $\mathrm{mmHg}$ & $12 \pm 8$ & $8 \pm 5$ & NS $(\mathrm{p}=0.2)$ \\
\hline Mixed venous oxygen saturation $\%$ & $56 \pm 15$ & $68 \pm 12$ & NS $(p=0.09)$ \\
\hline
\end{tabular}

BMI: body mass index; NYHA: New York Heart Association classification of dyspnoea.

1996. Among the remainder, 7 out of 14 exposed patients $(50 \%)$ died before the end of observation with a mean survival of $8 \pm 8$ months, and 3 out of 9 nonexposed cases (33\%) died with a mean survival of $23 \pm 10$ months (Ns, $\mathrm{p}=0.10)$. Among the 13 patients who were still alive at the end of observation, only 2 showed an improvement in symptoms and both of them were nonexposed patients.

\section{Discussion}

The present study showed that in the absence of any restriction to the prescription of appetite suppressants (like in Belgium until recently) more than half of the patients with primary pulmonary hypertension present with a history of previous intake of these drugs. Patients with previous intake of appetite suppressants appear to be more severely ill, with a more rapid progression of the disease, and a reduced survival.

The exposure rate of $66 \%$ to appetite suppressants found in the present study is much higher than in other series of patients with primary pulmonary hypertension, such as reported by a French reference centre $(20 \%, \mathrm{n}=73)$ [3], an English transplantation reference centre $(5 \%, \mathrm{n}=$ 55) [9], the American NIH Registry (5\%, $n=187$ ) [7] or the IPPHS (definite and possible use 35\%, $n=95$ ) [4]. It is however strikingly similar to the exposure rate of $62 \%$ ( $n=582$ cases recruited from 23 centres) reported during the epidemic of primary pulmonary hypertension which occurred with the release of the appetite suppressant drug aminorex in Austria, the Federal Republic of Germany, and Switzerland in the late 1960s [2].

Several biases could have led to an overestimation of the exposure to appetite suppressants in Belgium. Patients exposed to appetite suppressants would have been preferentially included in the study if they were more likely to: 1) have their disease recognized than other patients (diagnostic bias), or 2) be reported because clinicians considered them as more interesting for the study (reporting bias). There was indeed a higher exposure in the cases diagnosed after September 1992, which might be explained by an increased awareness during the course of the study about a possible association between appetite suppressants and primary pulmonary hypertension in the participating centres. However, an increased exposure may also have paralleled an increase in appetite suppressant sales registered in Europe, as attested by the observation that the 5 exposed controls all corresponded to cases diagnosed after September 1992. In addition, it seems unlikely that the diagnosis would have been accelerated in patients 
exposed to appetite suppressants. The delay between first symptoms and diagnosis tended to be lower in exposed cases, but their disease was also more advanced at the time of the diagnosis.

Another bias could have been that patients remember using appetite suppressants more often than controls (recall bias). The fact that exposure after the index date was about the same in controls and cases and that it also parallels the sales figures argues against this possibility. An underevaluation of the exposure was likely to occur during the interviews by interviewers without any medical background because a medical training is important to avoid the pitfalls of history-taking and to ask the adequate guiding questions. There was indeed a discrepancy between the objective information's from the medical records (such as original copies of the prescriptions for appetite suppressants), and a negative interview in 3 patients. The index date was reported to be earlier in the interviews than in the medical records in 13 patients, but this is probably an effect of repeated questioning. Accordingly, "all exposure" (definite and possible exposure) and the index dates of the medical records were used for analysis in the present study.

The ratio of females to males in the present study was 3.4:1, as compared to $2.3: 1$ in the IPPHS [4] and 1.7:1 in the American Registry [7]. The ratio of females to males was $4.5: 1$ in a series of patients with primary pulmonary hypertension during the aminorex epidemic [2]. In the IPPHS [4], patients exposed to appetite suppressants were slightly more severely affected at the time of diagnosis ( 89.7 versus $56.6 \%$ in NYHA class III and IV), with a shorter median delay between onset of symptoms and diagnosis (16.8 versus 17.6 months). The Belgian series shows a similar tendency, also supported by the fact that all the patients who died before the interview had been exposed to appetite suppressants. In the aminorex epidemic, the duration of symptoms before haemodynamic investigation was shorter, but the survival globally was better, with remissions and a median survival of 12 and $4.5 \mathrm{yrs}$ in the exposed and nonexposed cases respectively [2].

It may be worth noting that only 12 of the 23 patients with previous intake of appetite suppressants in the present study had severe obesity defined as a BMI $>30,2$ patients had a morbid obesity defined as a BMI $>40$, and only 6 patients had obesity-related systemic hypertension. Furthermore, no patient with previous intake of appetite suppressants presented with obesity-related diabetes or hypercholesterolaemia. These data suggest that overprescription may derive from the unrestricted prescription of appetite suppressants to treat obesity, perhaps because of the public health campaigns warning about the risks of excessive weight, and also cultural factors related to the aesthetics of the female image in advanced industrial countries.

Most appetite suppressants are structurally-related and derived from the phenylethylamine molecule [10]. They all act by increasing the release and decreasing the reuptake of serotonin at the presynaptic nerve endings [11], resulting in a prolongation or enhancement of the appetite suppressing effects of serotonin. These drugs also induce a depletion in platelet serotonin together with a rise in plasma serotonin, with decreasing effectiveness of the drugs from aminorex to diethylpropion and to phentermine [12]. It has been hypothesized that serotonin, in association with other vasoconstrictor stimuli such as hypoxia, could trigger the development of pulmonary hypertension in susceptible patients [13, 14]. An alternative hypothesis of a direct action of phenylethylamine-derived appetite suppressants has been proposed, based on the observation that fenfluramines and aminorex, like hypoxia, inhibit pot-assium current, and thereby cause membrane depolarization and the entry of calcium, initiating vasoconstriction [15].

A recent editorial calculated an "acceptable" benefit:risk ratio (20 lives saved for 1 death) for the treatment of obesity with dexfenfluramine after the approval of this drug by the American Food and Drug Administration [5]. The authors extrapolated the results of a 12 month trial of a large number of obese patients treated with dexfenfluramine, which produced an average weight reduction of $10 \%$ (omitting to consider a $7 \%$ weight reduction in a placebo group) [16], to mortality data according to the BMI derived from the large scale Nurses Health Study [17] leading to the estimation of 280 deaths prevented per million obese persons treated each year. They went on to multiply the odds ratio for primary pulmonary hypertension associated with appetite suppressant use for $>3$ months reported by the IPPHS, or 23, by a background risk of 1.2 per million persons $\cdot \mathrm{yr}^{-1}$, and by an assumed mortality of $50 \%$ for primary pulmonary hypertension, and concluded that treatment of obesity with appetite suppressants saves 280 lives as compared to 14 deaths by pulmonary hypertension per million persons for each years of treatment [5]. The present results suggest a higher odds ratio for pulmonary hypertension associated with anorexigen intake. In addition, fenfluramine-induced weight loss reverses when the medication is stopped [18, 19], and the risk of pulmonary hypertension tends to increase with duration of treatment [4]. Benefit to risk ratios in terms of mortality ignore the suffering that patients with primary pulmonary hypertension have to face, and which is at best only transiently relieved by heart-lung or lung transplantation [1]. No prospective randomized and double-blind study has demonstrated that appetite suppressants decrease mortality or morbidity in obese patients.

Very recently, dexfenfluramine, distributed under the names Redux ${ }^{\circledR}$ by Wyeth Ayers in the USA and Isomeride $\AA$ by Servier in Europe, and fenfluramine, distributed under the name Ponderal ${ }^{\circledR}$ by Servier in Europe, have been precipitously withdrawn from the market by these pharmaceutical companies after the report of a small observational study of 24 females with valvular heart disease associated with fenfluramine combined with phentermine [20]. Legal restriction to the prescription of fenfluramines as magistral preparations is currently being considered in Belgium.

Acknowledgements: The authors would like to thank the members of the IPPHS group and the active members of the Belgian reporting centres: M. Estenne, J.L. Vachiéry, J. Van Haecke, W. Van Mieghem, G. Verleden, R. Broux, L. Delaunois, D. Van Renterghem, Y. Bogaerts, J. Vanwelden, B. Van de Maele, P. Mengeot, E. Balthazar, W. Elinck, V. Legrand, M. Mairesse, M. DePauw, P. Van den Brande. 


\section{References}

1. Rubin LJ. Primary pulmonary hypertension. $N$ Engl $J$ Med 1997; 336: 111-117.

2. Gurtner HP. Aminorex pulmonary hypertension (chapter 29). In: Fishman AP, ed. The Pulmonary Circulation, Normal and Abnormal. Philadelphia, University of Pennsylvania Press, 1990; pp. 397-411.

3. Brenot F, Herve P, Petitpretz P, Parent F, Duroux P, Simonneau G. Primary pulmonary hypertension and fenfluramine use. Br Heart J 1993; 70: 537-541.

4. Abenhaim L, Moride Y, Brenot F, et al. Appetite-suppressant drugs and the risk of primary pulmonary hypertension. $N$ Engl J Med 1996; 335: 609-616.

5. Manson JE, Faich GA. Pharmacotherapy for obesity - do the benefits outweigh the risk? N Engl J Med 1996; 335: 659-660.

6. Voelkel NF, Clarke WR, Higenbottam T. Obesity, dexfenfluramine, and pulmonary hypertension. A lesson not learned? Am J Respir Crit Care Med 1997; 155: 786-788.

7. Rich S, Dantzker DR, Ayres SM, et al. Primary pulmonary hypertension. A national prospective study. Ann Intern Med 1987; 107: 216-223.

8. Armitage P, Berry G. Statistical Methods in Medical Research. Oxford, Blackwell Scientific Publications, 1987; pp. 104-115.

9. Thomas SHL, Butt AY, Corris PA, et al. Appetite suppressants and primary pulmonary hypertension in the United Kingdom. Br Heart J 1995; 74: 660-663.

10. Pinder RM, Brogden RN, Sawyer PR, Speight TM, Avery GS. Fenfluramine: a review of its pharmacological properties and therapeutic efficacy in obesity. Drugs 1975; 10 : 241-323.

11. McTavish D, Heel RC. Dexfenfluramine. A review of its pharmacological properties and therapeutic potential in obesity. Drugs 1992; 43: 713-733.

12. Fristrom S, Airaksinen MM, Halmekoski J. Release of platelet 5-hydroxytryptamine by some anorexic and other sympathomimetics and their acetyl derivatives. Acta Pharmacol Toxicol Copenh 1977; 41: 218-224.

13. Hervé P, Launay JM, Scrobohaci ML, et al. Increased plasma serotonin in primary pulmonary hypertension. Am J Med 1995; 99: 249-254.

14. Naeije R, Wauthy P, Maggiorini M, Leeman M, Delcroix M. Effects of dexfenfluramine on hypoxic pulmonary vasoconstriction and embolic pulmonary hypertension in dogs. Am J Respir Crit Care Med 1995; 151: 692-697.

15. Weir EK, Reeve HL, Huang JMC, et al. Anorectic agents aminorex, fenfluramine, and dexfenfluramine inhibit potassium current in rat pulmonary vascular smooth muscle and cause pulmonary vasoconstriction. Circulation 1996; 94: 2216-2220.

16. Guy-Grand B, Apfelbaum M, Crepaldi G, Gries A, Lefebvre P, Turner P. International trial of long-term dexfenfluramine in obesity. Lancet 1989; ii: 1142-1144.

17. Manson JE, Willett WC, Stampfer MJ, et al. Body weight and mortality among women. $N$ Engl J Med 1995; 333: 677-685.

18. Pfohl M, Luft D, Blomberg I, Schmülling RM. Longterm changes of body weight and cardiovascular risk factors after weight reduction with group therapy and dexfenfluramine. Int J Obes 1994; 18: 391-395.

19. O'Connor HT, Richman RM, Steinbeck KS, Caterson ID. Dexfenfluramine treatment of obesity: a double blind trial with post trial follow-up. Int J Obes 1995; 19: 181-189.

20. Connolly HM, Crary JL, McGoon MD, et al. Valvular heart disease associated with fenfluramine-phentermine. N Engl J Med 1997; 337: 581-588. 